\title{
Chemical vapor infiltration of pyrocarbon from methane pyrolysis: kinetic modeling with texture formation
}

\author{
Chunxia $\mathrm{Hu}^{1}$, Hejun $\mathrm{Li}^{1 *}$, Shouyang $\mathrm{Zhang}^{1}$, Wei $\mathrm{Li}^{1}$ and $\mathrm{Ni} \mathrm{Li}^{2 *}$
}

\begin{abstract}
A complete mechanism of methane pyrolysis is proposed for chemical vapor infiltration of pyrocarbon with different textures, which contains a detailed homogeneous mechanism for gas reactions and a lumped heterogeneous mechanism for pyrocarbon deposition. This model is easily applied to simulate gas compositions and pyrocarbon deposition in a vertical hot-wall flow reactor in the temperature range of 1,323-1,398 $\mathrm{K}$ without any adjusting parameters and presents better results than previous mechanisms. Results have shown that the consumption of methane and the production of hydrogen are well enhanced due to pyrocarbon deposition. Pyrocarbon deposition prevents the continuously increasing of acetylene composition and leads to the reduction in the mole fraction of benzene at long residence times in the gas phase. The carbon growth with active sites on the surface is the controlling mechanism of pyrocarbon deposition. $\mathrm{C}_{1}$ species is the precursor of pyrocarbon deposition at $1,323 \mathrm{~K}$, and the primary source over the whole temperature range. As temperature increases, gas phase becomes more mature and depositions from acetylene, benzene and polyaromatic hydrocarbons become more prevalent. A general pyrocarbon formation mechanism is derived with the specific precursors and illustrates that the maturation of gas compositions is beneficial to forming planar structures with hexagonal rings or pentagon-heptagon pairs, namely, high textured pyrocarbon. The results are in well agreement with experiments.
\end{abstract}

Keywords: kinetic modeling, pyrolytic carbon, texture, chemical vapor infiltration, methane

\section{INTRODUCTION}

Carbon materials are now experiencing booming development in various applications [1-3]. Aimed at well mechanical performance at high temperatures, carbon composites are developed with carbon or ceramic fibers, an interlayer coating (such as pyrocarbon) on the fibers, and a matrix of carbon or ceramic. The composites combine the advantages of fibers and matrixes and fulfill the demand in aerospace industry, for example, carbon fiber reinforced pyrocarbon $(\mathrm{C} / \mathrm{C})$ composites used as airplane brakes [4]. New properties have been revealed as time goes by and promote wide applications of the composites. The well biocompatibility and susceptibility under corrosion atmosphere and favorable mechanical properties equip $\mathrm{C} / \mathrm{C}$ composites as a novel biomaterial $[5,6]$. Carbon fiber reinforced multilayered pyrocarbonsilica matrix composites show good flexural strength, fracture toughness, electrical conductivity and electromagnetic interference shielding performance, which are very promising in eliminating electromagnetic interference for the protection of sensitive devices and environments $[7,8]$.

In order to fabricate the composites, a well-known technology is chemical vapor infiltration (CVI), consisting of gas pyrolysis producing various intermediates and solid matrix deposition on the fiber surfaces. The gaseous precursors could be hydrocarbons for pyrocarbon deposition or chlorosilanes for silicon deposition. With the technology, no damage is made on fibers and the matrix shows fine properties. Meanwhile, a high bonding strength of fiber/matrix is produced, which is very important for the composite applications. The process is a combination of chemical reactions, gas flow, mass transfer and heat transfer. Thus, with different parameters, the matrix, for example, pyrocarbon, is formed with different nanotextures, which are low, medium and high textured pyrocarbons distinguished by the orientation angles [9] and produce a significant impact on the

\footnotetext{
${ }^{1}$ State Key Laboratory of Solidification Processing, C/C Composites Research Center, Northwestern Polytechnical University, Xi'an 710072, China

${ }^{2}$ Department of Mechanical Engineering, California State University, Los Angeles, CA 90032, USA

* Corresponding authors (emails: lihejun@nwpu.edu.cn (Li H); nli12@calstatela.edu (Li N))
} 
composite properties [10]. To manufacture composites with pyrocarbon of a desired texture, a better understanding of the pyrocarbon formation mechanism in CVI process is in an urgent demand.

Hüttinger et al. [11,12] investigated the influence of CVI conditions (temperatures, pressures, surface area/ volume ratios) on pyrocarbon deposition from methane pyrolysis by experiments, resulting a pure high-textured carbon matrix at $1,095^{\circ} \mathrm{C}$ and a lower textured carbon at lower temperatures. The formation mechanism for pyrocarbon in different textures was discussed based on the aromatic growth [13]. The qualitative analysis shows clear insight of the forceful influence on pyrocarbon deposition and formation by CVI parameters, while little attention was paid to the nature of methane pyrolysis. Later, details of hydrocarbon pyrolysis in the gas phase during CVI were studied. Norinaga et al. [14,15] analyzed the gas phase compounds from ethylene, acetylene and propylene pyrolysis in CVI of pyrocarbon with a honeycomb monolith as the preform in a vertical flow reactor. A detailed kinetic model with 227 species and 827 elementary reactions was developed. Nevertheless, although the mole fractions of gas intermediates were well reproduced by the mechanism, the model actually ignored the pyrocarbon deposition on the preform. Devin-Ziegler et al. [16-18] studied the pyrolysis of propane for CVI of pyrocarbon by experiments and simulations in a jet stirred reactor. The special reactor, although not widely used in composite preparations in industry, has the advantage of providing the uniform gas composition in the whole volume. A detailed kinetic mechanism of 608 reactions with 172 species was proposed and able to reproduce the molar fractions of major gas products up to pyrene $\left(\mathrm{C}_{16} \mathrm{H}_{10}\right)$. Lumped heterogeneous reactions for pyrocarbon deposition were calculated based on the experimental species concentrations and pyrocarbon deposition rates, declaring that smooth laminar pyrocarbon was quantitatively formed with small unsaturated species (ethylene and acetylene). Regretfully, no further discussion was presented regarding the formation mechanism of pyrocarbon in different textures.

The aim of this work is to propose a complete mechanism of methane pyrolysis for pyrocarbon formation with different textures in CVI process. We choose methane as the gas precursor in this work, for the reason that it is the ideal hydrocarbon for various reasons [19] and quite easy to be acquired with low cost in industry. In the second section of this paper, experimental methods to obtain gas compositions and deposition rates of pyrocarbon in CVI were listed in general. In the third section, the kinetic model for methane pyrolysis with pyrocarbon deposition during CVI was described. Comparisons between the experimental and simulation results of mole fractions of gas intermediates and pyrocarbon deposition rates were shown in the fourth section. And the precursors to deposit pyrocarbon in methane pyrolysis were clarified. In the last section, the formation mechanism of pyrocarbon with different textures was analyzed based on the resulting pyrocarbon precursors.

\section{EXPERIMENTAL METHOD}

Studies of methane pyrolysis and pyrocarbon deposition have begun previously and the detailed description of experimental setups has been presented [20-22]. Here only the essential features are recalled. The pyrolysis was carried out in a vertical hot-wall flow reactor with an alumina-ceramic-tube deposition area of $22 \mathrm{~mm}$ in diameter and $20 \mathrm{~mm}$ in length. The deposition area is connected with the gas inlet by a narrow tube of $8 \mathrm{~mm}$ in diameter and a conical nozzle of $60^{\circ}$ in angle to avoid the pre-decomposition of methane before arriving at the deposition area and to generate a plug-flow gas flow $[22,23]$. Methane pyrolysis in an empty deposition area is considered as pure gas-phase reactions, since the pyrocarbon deposition could be neglected considering a small area/volume ratio of $0.28 \mathrm{~mm}^{-1}$. For studying pyrocarbon deposition, a honeycomb structure made of cordierite is located in the deposition area to improve the area/volume ratio. The honeycomb structure has 62 square shaped channels per $\mathrm{cm}^{2}$. The cross-section of each channel is around $1.1 \mathrm{~mm}^{2}$ and the wall thickness amounts to $0.18 \mathrm{~mm}$. Pre-deposition of the honeycomb structure was done for nearly $20 \mathrm{~h}$ in order to fill the pore entrance on the surface and to get rid of its porous structure [21]. Any diffusion influence on pyrocarbon deposition and formation is excluded as the porous structure in this preform is simple long straight pores. Fig. 1 presents the schematic of the reactor and the cross-section of a preform.

The experiments were performed at a residence time of $1 \mathrm{~s}$ and a total pressure of $100 \mathrm{kPa}$ with an initial ratio of methane pressure/argon pressure at 1:9. The temperature varied from 1,323 to $1,398 \mathrm{~K}$. The deposition rate was derived from the mass increase of the honeycomb structure related with the surface area. A Poropak- $\mathrm{R}$ column and a CP Sil 5 CB column were used to separate the gaseous and liquid products in methane pyrolysis. The gaseous products were analyzed with a Siemens Sichromat 1 gas chromatograph equipped with a gas split, a TCD- and a FID-detector. The liquid products were 


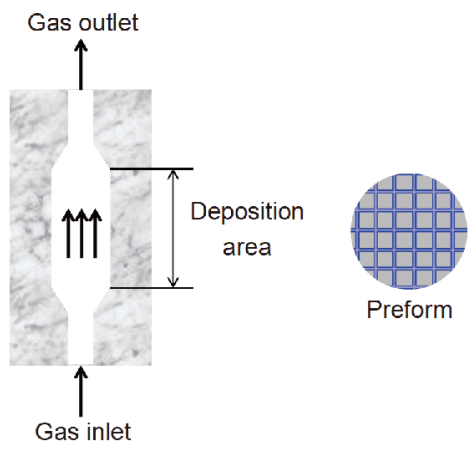

Figure 1 Schematic of the reactor and the cross-section of a preform.

dissolved in acetone and analyzed with a Siemens Sichromat 1-4 gas chromatograph equipped with a FIDdetector $[22,23]$.

\section{MODELING OF PYROCARBON DEPOSITION}

\section{Homogeneous reactions}

Methane pyrolysis produces various hydrocarbons and radicals, ranging from light species, such as hydrogen or methyl, to polyaromatic species, such as pyrene $\left(\mathrm{C}_{16} \mathrm{H}_{10}\right)$. In order to reproduce their experimental concentrations, a detailed mechanism with gas elementary reactions had been developed by $\mathrm{Hu}$ et al. [24]. The mechanism is composed of 909 reversible elementary reactions and 241 radicals and molecules. The reactions, including homolytic dissociation reactions, radical recombination reactions, radical/molecular disproportionation reactions, $\beta$ scission reactions, radical addition reactions, hydrogen abstraction reactions and isomerization reactions, are primarily collected from various literatures. The primary reaction mechanism of $\mathrm{C}_{1}-\mathrm{C}_{4}$ species in methane pyrolysis is derived from the reaction scheme obtained by Becker et al. $[20,23,25]$. Reactions of $\mathrm{C}_{3}-\mathrm{C}_{4}$ species in Hidaka's mechanism [26] and Tsang's mechanism [27] are added additionally. $\mathrm{C}_{5}-\mathrm{C}_{9}$ reactions are those proposed by Marinov et al. [28] related to the combustion mechanism of methane and ethane premixed flames. Reactions with large polyaromatic hydrocarbons are collected from mechanisms proposed by Richter et al. [29] or Norinaga et al. [30]. The kinetic parameters of reactions and thermodynamic parameters of species are inherited from the related references. Pressure effects on pressuredependent reactions involving small species are described by Troë parameters [31]. The mechanism has been verified to be able to simulate the species concentrations when pyrocarbon deposition can be ignored [24].

\section{Heterogeneous reactions}

Pyrocarbon is assumed to be deposited by heterogeneous reactions between species and solid surface, as shown in the following:

$\mathrm{C}_{m} \mathrm{H}_{n} \stackrel{\mathrm{C}(\mathrm{S})}{\longrightarrow} m \mathrm{C}(\mathrm{B})+\frac{n}{2} \mathrm{H}_{2}$,

where $C(S)$ is the active site on the surface and $C(B)$ is the carbon atom newly-grown on the surface. No reversible reactions are mentioned, assuming that once pyrocarbon is deposited, it will not react to produce gas species again. Here three types of deposition reactions are considered: (1) Reactions with $\mathrm{CH}_{x(x \leq 4)}$ formed by methane dehydrogenation. Simulation studies [32] based on density functional theory have shown that the highest energy barrier for methane dehydrogenation is close to the activation energy of carbon deposition with methane pyrolysis and experimental results [20,22,33] have shown that the deposition rate at zero residence time is larger than zero, both indicating that pyrocarbon could be deposited quickly with methane or its dehydrogenation products, i.e., $\mathrm{CH}_{x(x \leq 4)}$. $\mathrm{CH}_{3}$ has been successfully considered as a main reactant in deposition simulations with elementary surface reactions [34-36]. Meanwhile, the concentration of methane with or without pyrocarbon deposition is quite different, which will be compared in quantity in the next section.

(2) Reactions with small species formed in methane pyrolysis, for example, $\mathrm{C}_{2}$ species. These species are with the second largest concentrations in the gas phase. Ethylene with a double bond and acetylene with a triple bond are highly active and have similar bonds with those in pyrocarbon, which seems to be involved in reactions of pyrocarbon deposition. Previous research has underlined that acetylene addition is an important way to produce pyrocarbon in ethylene, acetylene and propane pyrolysis $[18,23]$.

(3) Reactions with large species formed in methane pyrolysis, such as $\mathrm{C}_{6} \mathrm{H}_{6}$. This group of species is interesting for their comparable structures with that of pyrocarbon, although their concentrations are much lower than those of small species. Besides, benzene has been considered as the significant "particle" in the popular "particle filler theory" [13] for pyrocarbon deposition.

The kinetic parameters of heterogeneous reactions are calculated from the experimental deposition rates of pyrocarbon. For Reaction (I), the deposition rate $\left(\mathrm{mol} \mathrm{m}{ }^{-2} \mathrm{~h}^{-1}\right)$ is expressed as

$r=m k[\mathrm{C}(\mathrm{S})]\left[\mathrm{C}_{m} \mathrm{H}_{n}\right]$,

where $k$ is the rate constant of bimolecular reactions 
$\left(\mathrm{m}^{3} \mathrm{~mol}^{-1} \mathrm{~h}^{-1}\right), \quad\left[\mathrm{C}_{m} \mathrm{H}_{n}\right]$ is the species concentration $\left(\mathrm{mol} \mathrm{m}^{-3}\right)$ without pyrocarbon deposition and $[\mathrm{C}(\mathrm{S})]$ is the active site density on the surface, expressed in $\mathrm{mol} \mathrm{m}{ }^{-2}$. Suppose that the rate constant follows the Arrhenius law in the temperature range studied (1,323$1,398 \mathrm{~K})$. The activation energies and Arrhenius factors of deposition reactions are estimated by plotting the logarithms of the reaction rate constants $v s$. the inverse of the temperatures. Aimed at getting the reaction rate constant, the experimental deposition rate is used as an input in Equation (1). $\left[\mathrm{C}_{m} \mathrm{H}_{n}\right]$ is calculated by homogeneous reactions, indicating the species concentration before pyrocarbon deposition. Since $[\mathrm{C}(\mathrm{S})]$ is usually considered to be constant [34-36] and multiplying the reaction rate constant by a constant has no influence on its trend, $[\mathrm{C}(\mathrm{S})]$ is combined with the reaction rate constant to avoid the complexity and inaccuracy of describing the pyrocarbon surface, leading to

$r=m k^{\prime}\left[\mathrm{C}_{m} \mathrm{H}_{n}\right]$

with $k^{\prime}=k[\mathrm{C}(\mathrm{S})]$ named as the "apparent" reaction rate constant. Henceforth the reaction rate constants of heterogeneous reactions are replaced by the "apparent" reaction rate constants unless otherwise specified.

With this simplification, the heterogeneous reactions can be treated as "apparent" homogeneous gas reactions and added into the homogeneous reaction mechanism with their Arrhenius parameters. As the pyrocarbon deposition rate is quite small, the appearance of "gaseous" pyrocarbon will have little influence on the total pressure in the reactor. The "apparent" homogeneous reaction mechanism is used in the same way as the purely homogeneous reaction mechanism. Species concentrations and pyrocarbon deposited are given in mole fractions of the total "gas" phase. The concentration of major species and the deposition rate can be calculated as

$\left[\mathrm{C}_{m} \mathrm{H}_{n}\right]=\frac{X_{\mathrm{C}_{m} \mathrm{H}_{n}} \times P}{R \times T}$

$r=\frac{X_{\mathrm{C}(\mathrm{B})} \times P \times V}{R \times T \times S \times \tau}$

where $X_{\mathrm{C}_{m} \mathrm{H}_{n}}$ and $X_{\mathrm{C}(\mathrm{B})}$ are simulated mole fraction of species $\mathrm{C}_{m} \mathrm{H}_{n}$ and pyrocarbon $\mathrm{C}(\mathrm{B}), P$ is the total pressure, $V$ is the reactor volume, $R$ is the gas constant, $T$ is the reacting temperature, $S$ is the surface area of the reactor, and $\tau$ is the residence time.

\section{Reactor flow model}

According to the experimental setup, the deposition area in the reactor is tubular and the gas flow is a plug flow.
The plug flow in a tubular area gets rid of the transverse diffusion in the axial direction and assumes the perfect mixing in the radical direction, which can be easily described by one-dimensional equations. Hence, under the experimental conditions, the equations for this "onedimensional" chemical reacting flow are the first-order ordinary differential equations (ODEs) with the axial coordinate variable, satisfying:

the mass continuity equation

$\rho u \frac{\mathrm{d} A}{\mathrm{~d} x}+\rho A \frac{\mathrm{d} u}{\mathrm{~d} x}+u A \frac{\mathrm{d} \rho}{\mathrm{d} x}=A_{\mathrm{L}} \sum_{k=1}^{K_{\mathrm{g}}} \dot{s}_{k} M_{k} ;$

the species conservation equation

$\rho u A \frac{\mathrm{d} Y_{k}}{\mathrm{~d} x}+Y_{k} A_{\mathrm{L}} \sum_{k=1}^{K_{\mathrm{g}}} \dot{s}_{k} M_{k}$

$=M_{k}\left(A_{\mathrm{L}} \dot{s}_{k}+A \dot{\omega}_{k}\right)$;

the energy equation

$u A\left(\sum_{k=1}^{K_{\mathrm{g}}} h_{k} \frac{\mathrm{d} Y_{k}}{\mathrm{~d} x}+\bar{C}_{p} \frac{\mathrm{d} T}{\mathrm{~d} x}+u \frac{\mathrm{d} u}{\mathrm{~d} x}\right)$

$+\left(\sum_{k=1}^{K_{\mathrm{g}}} h_{k} Y_{k}+\frac{1}{2} u^{2}\right) A_{\mathrm{L}} \sum_{k=1}^{K_{\mathrm{g}}} s_{k} M_{k}$

$=A_{\mathrm{L}} Q_{\mathrm{e}}-A_{\mathrm{L}} \sum_{k=K_{b}^{f}}^{K_{b}} s_{k} M_{k} h_{k} ;$

the momentum equation

$A \frac{\mathrm{d} P}{\mathrm{~d} x}+\rho u A \frac{\mathrm{d} u}{\mathrm{~d} x}+\frac{\mathrm{d} F}{\mathrm{~d} x}+u A_{\mathrm{L}} \sum_{k=1}^{K_{\mathrm{g}}} s_{k} M_{k}=0$.

In the above equations, $x$ represents the axial coordinate, $\rho$ is the mass density, $u$ is the axial velocity, $K_{\mathrm{g}}$ is the number of gas species, $A_{\mathrm{L}}$ is the surface area per unit length, $A$ is the cross-section area of the reactor, $\dot{s}_{k}$ is the molar production rate of species $k$ by all surface reactions, $M_{k}$ is the molecular weight of species $k, \omega_{k}$ is the molar production rate by gas reactions, $Y_{k}$ is the mass fraction of species $k, h_{k}$ is the specific enthalpy of species $k, C_{p}$ is the mean heat capacity per unit mass of gases, $T$ is the absolute gas temperature, $Q_{\mathrm{e}}$ is the heat flux from the surrounding to the tube wall, $K_{b}$ is the number of surface species, $P$ is the absolute pressure, $F$ is the drag force exerted on the gases by the tube wall, which is expressed in terms of a friction factor $f$ :

$\frac{\mathrm{d} F}{\mathrm{~d} x}=A_{\mathrm{L}} \frac{1}{2} \rho u^{2} f$.

Since constant temperature and pressure are used in the calculations to simulate the isothermal isobaric experi- 
mental condition, the energy equation is provided only for the sake of completeness and not solved in the simulations. Furthermore, all terms containing parameters related with surface species vanish for the surface reactions being treated as the "apparent" homogeneous gas reactions. The direct-solution method in DASPK [37] is employed to solve the resulting system of ODEs, which adopts backwards-differencing methods for the integration of different species.

\section{COMPARISON BETWEEN SIMULATIONS AND EXPERIMENTS}

In the following part, we will discuss pyrocarbon deposited from the dehydrogenation products $\mathrm{CH}_{x(x \leq 4)}$, the small species acetylene and the large species benzene. Simulation results of gas mole fractions and pyrocarbon deposition rates are compared with the experimental data published by Hüttinger et al. [22,33]. The conclusion of these analyses will lead to consideration of a combined deposition mechanism with various species, which delivers better simulation results than previous heterogeneous mechanisms by Tang [36], Lacroix [35] and Li [38].

\section{$\mathrm{CH}_{x(x \leq 4)}$ deposition}

The pyrocarbon deposition with $\mathrm{CH}_{x(x \leq 4)}$ and its kinetic parameters calculated based on the Arrhenius law are as following:

$\mathrm{CH}_{x(x \leq 4)} \stackrel{\mathrm{C}(\mathrm{S})}{\longrightarrow} \mathrm{C}(\mathrm{B})+\frac{x}{2} \mathrm{H}_{2}$,

$A=1.98 \times 10^{8}, E=226.89 \mathrm{~kJ} \mathrm{~mol}^{-1}$.

The plot for parameter determinations is illustrated in Fig. S1a in Supplementary information. The logarithmic rate constant of $\mathrm{CH}_{x(x \leq 4)}$ deposition has a good linear relationship with the inverse of temperature, with an adjusted $R^{2}$ (adj. $R^{2}$ ) of 0.997 . Fig. 2 depicts the pyrocarbon deposition rates at the residence time of $1 \mathrm{~s}$ measured in experiments (symbols) and simulations (lines). The comparison shows that $\mathrm{CH}_{x(x \leq 4)}$ can quantitatively be the precursor of pyrocarbon only at $1,323 \mathrm{~K}$. When temperature increases, the experimental data shows a clear exponential increase while the simulation deposition rate by $\mathrm{CH}_{x(x \leq 4)}$ increases linearly. This gives a sign that more species are able to deposit on the surface at high temperatures. Fig. 3 shows comparisons of gas phase mole fractions between experimental (symbols) and simulation results (lines). The dash lines and solid lines are the simulation results without or with pyrocarbon deposition, respectively. The low concentrations of acetylene and benzene in the gas phase at 1,323 K, as well as the small diffusion coefficients [19], limit the reactions

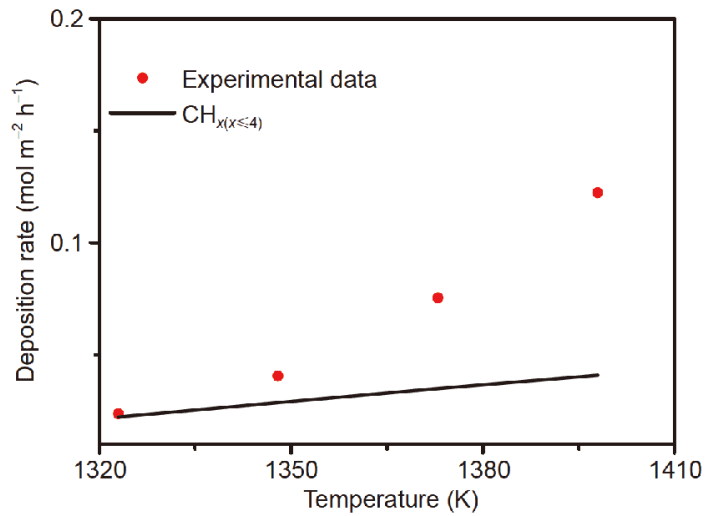

Figure 2 Comparison of pyrocarbon deposition rates at $1 \mathrm{~s}$ between experimental data and simulation results from $\mathrm{CH}_{x(x \leq 4)}$ deposition at different temperatures. Symbols represent experimental results, while the line is simulation results.

between species and deposition surface, illustrating the quite well consistency between the $\mathrm{CH}_{x(x \leq 4)}$ deposition rate and the experimental result. With the increasing temperature, mole fractions of methane decrease, while those of the other main species show opposite trends, indicating the increasing maturation of gas species and the enhanced possibility of more gas species to be involved in the pyrocarbon deposition. The consideration of pyrocarbon deposited from $\mathrm{CH}_{x(x \leq 4)}$ makes a more consistent modeling of gas concentrations. An obvious additional consumption of methane and a clearly increasing production of hydrogen are observed with the reaction of pyrocarbon deposition. The underestimation of methane mole fraction at low temperatures and long residence times is due to the inaccuracy of methane gas phase reaction rates, as mole fractions of methane simulated with homogeneous reactions are similar with those measured in experiments with pyrocarbon deposition. Slight decreases in mole fractions of $\mathrm{C}_{2}$ species occur, especially at long residence times. A better agreement is displayed for benzene mole fractions when pyrocarbon deposition is considered, except at 1,323 $\mathrm{K}$. This has been noticed even when no pyrocarbon deposition is involved in the simulation, illustrating that the deviation is inhibited from the inaccuracy of pure homogeneous reactions at $1,323 \mathrm{~K}$.

\section{Acetylene deposition}

The reaction of acetylene deposition and related kinetic parameters are listed below:

$$
\begin{aligned}
& \mathrm{C}_{2} \mathrm{H}_{2} \stackrel{\mathrm{C}(\mathrm{S})}{\longrightarrow} 2 \mathrm{C}(\mathrm{B})+\mathrm{H}_{2}, \\
& A=3.82 \times 10^{3}, E=96.26 \mathrm{~kJ} \mathrm{~mol}^{-1} .
\end{aligned}
$$



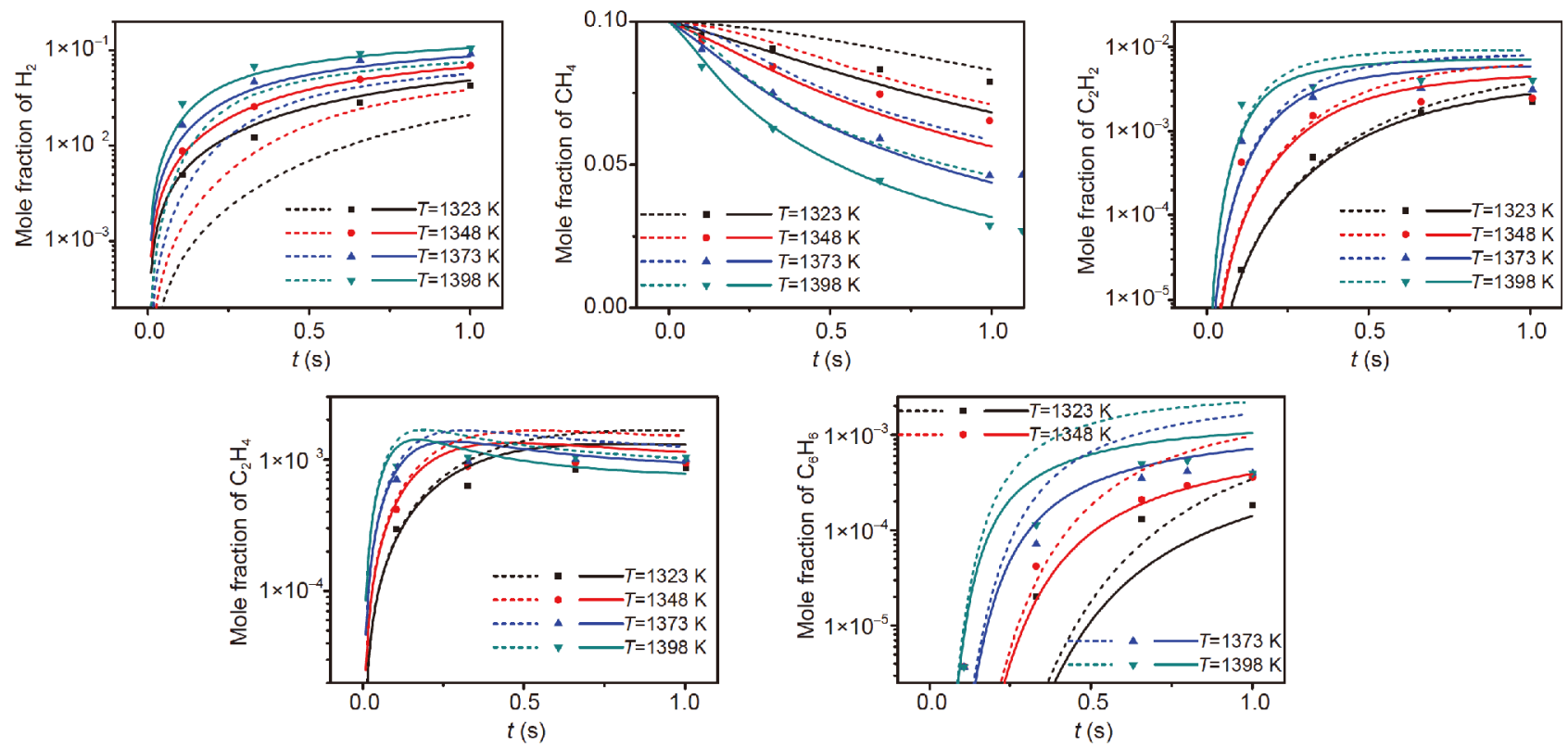

Figure 3 Mole fraction variations of gas species at different residence times and different temperatures. Symbols: experimental results; dash lines: simulation results with pure homogeneous reactions and solid lines: simulation results with $\mathrm{CH}_{x(x \leq 4)}$ deposition reaction.

The plot of parameter determinations is presented in Fig. S1b (red solid line) in Supplementary information. The adj. $R^{2}$ of the fitting line is 0.827 because $\ln k$ at $1,323 \mathrm{~K}$ is higher than the expected value according to variations of the other points. Fig. 4 depicts the comparison of pyrocarbon deposition rates at $1 \mathrm{~s}$ between simulations and experiments. Acetylene deposition rates from simulations show a slight exponential increase with the increase of temperature, while the values are much smaller than the experimental results within the temperature range considered. We could expect that acetylene may be one of the precursors for pyrocarbon deposition. Fig. S2 presents the mole fractions of major gases computed with homogenous and heterogeneous reactions (solid lines) and with pure gas-phase mechanisms (dash lines), and the counterparts from experiments (symbols).The involvement of pyrocarbon deposition by acetylene in the simulation mechanism leads to reduced mole fractions of $\mathrm{C}_{2}$ species and $\mathrm{C}_{6}$ species, which are more comparable to experimental results (shown in Fig. S2). Calculated mole fractions of $\mathrm{C}_{2} \mathrm{H}_{2}$ show similar variation trends with the experimental results, although the absolute values are larger than those from experiments. The hydrogen mole fractions at different temperatures are not influenced by the involvement of the heterogeneous reaction, because of the low $\mathrm{C} / \mathrm{H}$ ratio in acetylene. A slight increase of methane mole fraction is

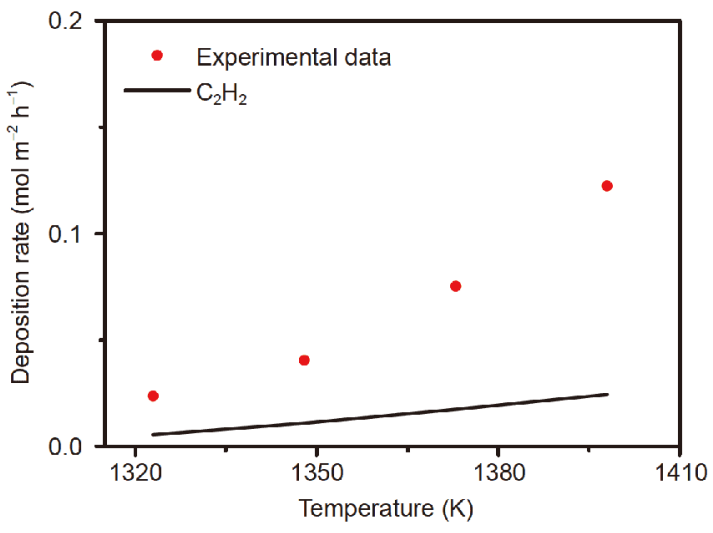

Figure 4 Comparison of pyrocarbon deposition rates at $1 \mathrm{~s}$ between experimental data and simulation results from acetylene deposition at different temperatures. Symbols represent experimental results, while the line is simulation results.

shown in pyrocarbon deposition process, indicating that the presence of pyrocarbon deposition has influenced the reaction pathways, for example, some hindered routes of methane consumption under this situation.

Except acetylene, ethylene and ethane are also small species, which show large mole fractions in methane pyrolysis for pyrocarbon deposition and may have a great influence on pyrocarbon deposition. Similar analyses have been done with all $\mathrm{C}_{2}$ species by taking the de- 
position rate as

$$
\begin{aligned}
r= & 2 k_{\mathrm{C}_{2} \mathrm{H}_{2}}^{\prime}\left[\mathrm{C}_{2} \mathrm{H}_{2}\right]+2 k_{\mathrm{C}_{2} \mathrm{H}_{4}}^{\prime}\left[\mathrm{C}_{2} \mathrm{H}_{4}\right] \\
& +2 k_{\mathrm{C}_{2} \mathrm{H}_{6}}^{\prime}\left[\mathrm{C}_{2} \mathrm{H}_{6}\right] .
\end{aligned}
$$

However, the simulation results (deposition rates and mole fractions of gas species) are almost the same with those from only acetylene deposition in the mechanism. This is expected as acetylene has the largest mole fraction among the three species and is the most active based on the reactivity of $\mathrm{C}_{2}$ species with aromatic hydrocarbons [39]. Therefore, for the simple and easy application, only acetylene deposition is presented and discussed here.

\section{Benzene deposition}

The reaction of benzene deposition and its kinetic parameters are:

$\mathrm{C}_{6} \mathrm{H}_{6} \stackrel{\mathrm{C}(\mathrm{S})}{\longrightarrow} 6 \mathrm{C}(\mathrm{B})+3 \mathrm{H}_{2}$,

$A=3.24 \times 10^{4}, E=111.15 \mathrm{~kJ} \mathrm{~mol}^{-1}$.

The determination plot of these parameters is presented in Fig. S1c (red solid line) in Supplementary information. It should be mentioned that although a line is fitted, its adj. $R^{2}$ is negative $(-0.44)$ because of an "abnormal" value of $\ln k$ at $1,323 \mathrm{~K}$. Considering the inaccuracy of benzene mole fraction at $1,323 \mathrm{~K}$ obtained with the homogeneous simulation, the experimental data has been used to replace the simulated mole fraction and no improvement is observed, implying that benzene deposition is not following Arrhenius law in the whole temperature range of 1,323-1,398 K. Yet, the simulations with Reaction (IV) have shown something new of reproducing experimental phenomena. Fig. 5 gives the comparison between the experimental and simulated deposition rates of pyrocarbon at $1 \mathrm{~s}$ from benzene at different temperatures. The simulated results present a more clearly exponential increase than those from methane or acetylene deposition, giving a positive suggestion for the involvement of benzene deposition at high temperatures. The smaller deposition rates by benzene at all temperatures show that there are other species that can be precursors for carbon deposition. The simulated deposition rate at $1,323 \mathrm{~K}$ is quite large and breaks the decreasing trend with the decreasing temperature, which is expected as a result of the negative adj. $R^{2}$.

The benzene mole fractions with benzene deposition are presented in Fig. 6. Symbols are the experimental data while solid and dash lines are simulation results with or without the heterogeneous reaction. Mole fractions of other main species are left out, as there is no difference between the simulation results with and without benzene

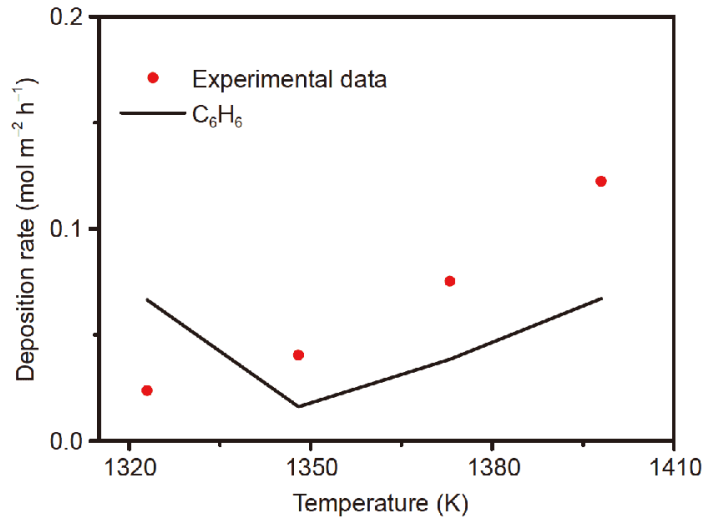

Figure 5 Comparison of pyrocarbon deposition rates at $1 \mathrm{~s}$ between experimental data and simulation results from benzene deposition at different temperatures. Symbols represent experimental results, while the line is simulation results.

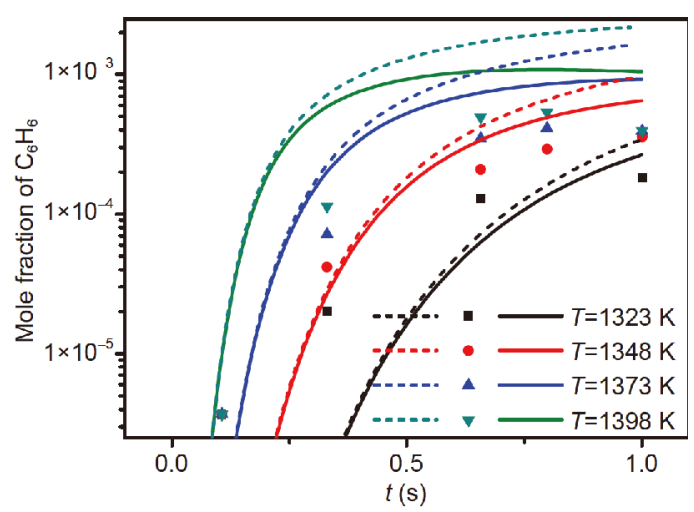

Figure 6 Mole fraction variations of benzene at different residence times and different temperatures. Symbols: experimental results; dash lines: simulation results with pure homogeneous reactions and solid lines: simulation results with benzene deposition reaction.

deposition in the simulation mechanism. This is reasonable, since benzene is a minor product and is produced after some pre-reaction time (0.1-0.4 s depending on the reaction temperature). The decrease of the benzene mole fraction at long residence times is simulated for the first time, confirming that benzene is one of the precursors for pyrocarbon deposition.

Only one aromatic hydrocarbon, benzene, is considered, whereas several kinds of polyaromatic hydrocarbons are produced in methane pyrolysis. The other polyaromatic hydrocarbons for pyrocarbon deposition are left out for the mole fraction of each polyaromatic hydrocarbon being quite small, varying from $10^{-5}$ to $10^{-18}$ in the homogeneous simulations. The quantitative experimental data of each polyaromatic hydrocarbon is still being tested, since these small values vary significantly in 
several analyses at the same experimental situation with an uncertainty of $\pm 32 \%$ [15]. As an even stronger exponential increase in pyrocarbon deposition rates is observed from the experiments at high temperatures, polyaromatic hydrocarbons are likely to be involved in pyrocarbon deposition at high temperatures. Further discussion about pyrocarbon deposition by polyaromatic hydrocarbons will be given in the following section.

\section{Combination deposition}

As discussed above, we can conclude that at the low temperature $(1,323 \mathrm{~K})$, pyrocarbon deposition is from $\mathrm{CH}_{x(x \leq 4)}$ and as temperature increases $(1,348-1,398 \mathrm{~K})$, a combination of $\mathrm{CH}_{x(x \leq 4)}$, acetylene and aromatic hydrocarbons produces pyrocarbon. Based on this rule, the Arrhenius parameters of acetylene and benzene deposition are recalculated (as shown in Fig. S1b and c (dash blue line) in Supplementary information):

$\mathrm{C}_{2} \mathrm{H}_{2} \stackrel{\mathrm{C}(\mathrm{S})}{\longrightarrow} 2 \mathrm{C}(\mathrm{B})+\mathrm{H}_{2}$,

$A=1.69 \times 10^{5}, E=139.80 \mathrm{~kJ} \mathrm{~mol}^{-1}$;

$\mathrm{C}_{6} \mathrm{H}_{6} \stackrel{\mathrm{C}(\mathrm{S})}{\longrightarrow} 6 \mathrm{C}(\mathrm{B})+3 \mathrm{H}_{2}$,

$A=1.33 \times 10^{7}, E=180.21 \mathrm{~kJ} \mathrm{~mol}^{-1}$.

The adj. $R^{2}$ has been improved to be over 0.9 for both reactions without the data at $1,323 \mathrm{~K}$. Polyaromatic hydrocarbons with more than six carbon atoms are taken as a whole in pyrocarbon deposition to avoid the inaccuracy introduced by several small values. The kinetic parameters for the deposition from polyaromatic hydrocarbons are analogized from those of benzene deposition, because of the similar structures among aromatic hydrocarbons. According to the results of homogeneous simulations, mole fractions of polyaromatic hydrocarbons are normalized to $\mathrm{C}_{6}$ and the total value is even smaller than that of benzene at 1,323 and $1,348 \mathrm{~K}$ and in the same order at 1,373 and $1,398 \mathrm{~K}$. Therefore, pyrocarbon depositions from polyaromatic hydrocarbons are supposed to happen at $>1,348 \mathrm{~K}$ with a mature gas phase.

Based on the above heterogeneous reactions, pyrocarbon depositions are analyzed along with the homogeneous reactions. The simulated pyrocarbon deposition rates at $1 \mathrm{~s}$ from each separate species are presented in columns with different fill patterns in Fig. 7. Compared with experimental data, the pyrocarbon deposition rates are reproduced very well with the largest deviation of $12 \%$ at $1,398 \mathrm{~K}$. This deviation indicates the improved importance of polyaromatic hydrocarbons in pyrocarbon deposition. With the increase of the temperature, gas compositions become more mature and pyrocarbon de-

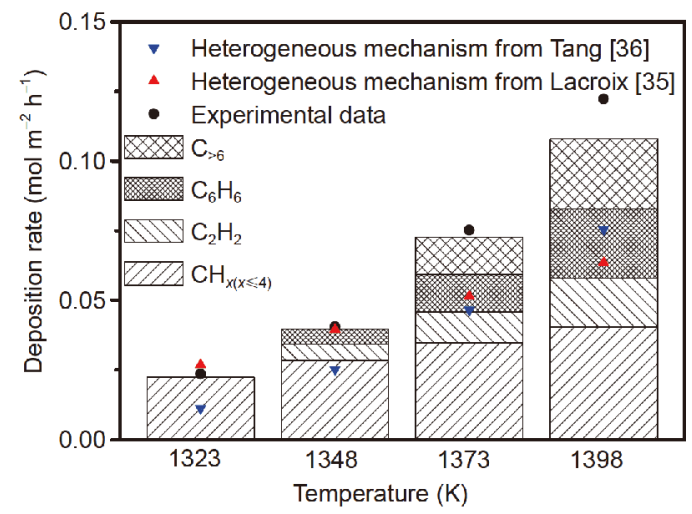

Figure 7 Variations of pyrocarbon deposition rates $v s$. temperature at a residence time of $1 \mathrm{~s}$. Symbols are simulation results from previous heterogeneous mechanisms and experimental results and columns with different fill patterns represent pyrocarbon deposited from different species in the present mechanism.

posited from aromatic hydrocarbons increases exponentially and becomes the dominated part. More accuracy information about large polyaromatic hydrocarbons is required for a better agreement, which will be revealed in the future work. The present simulation deposition rates have also been compared with simulation results from heterogeneous mechanisms with elementary reactions by Tang [36] and Lacroix [35], as shown in Fig. 7. The mechanism from Tang generates a clear exponential increase of deposition rates with the increase of temperature, although it underestimates the values over the whole temperature range. The mechanism from Lacroix predicts the deposition rates quite well at low temperatures while gives lower values at high temperatures. These indicate that the hypothesis of elementary reactions still needs improvements and more polyaromatic hydrocarbons should be involved in pyrocarbon deposition at high temperatures. What should be mentioned is that simulations with elementary surface reactions include much more variables to be solved than the present one and are usually hard to converge. Simulations of deposition rates with lump heterogeneous reactions from $\mathrm{Li}$ [38] have been done as well, leading to quite small values $\left(<10^{-2} \mathrm{~mol} \mathrm{~m}^{-2} \mathrm{~h}^{-1}\right)$. This is reasonable as the surface reactions were derived with the carbon deposition rates in various carbon fiber preforms, in which pore structures are complicated and gas diffusion has a nonnegligible effect on carbon deposition. The reaction rates in the heterogeneous mechanism from Li were a combination of the true deposition rates and the inhibition effect of gas diffusion on carbon deposition.

Mole fractions of major gas species are simulated with 

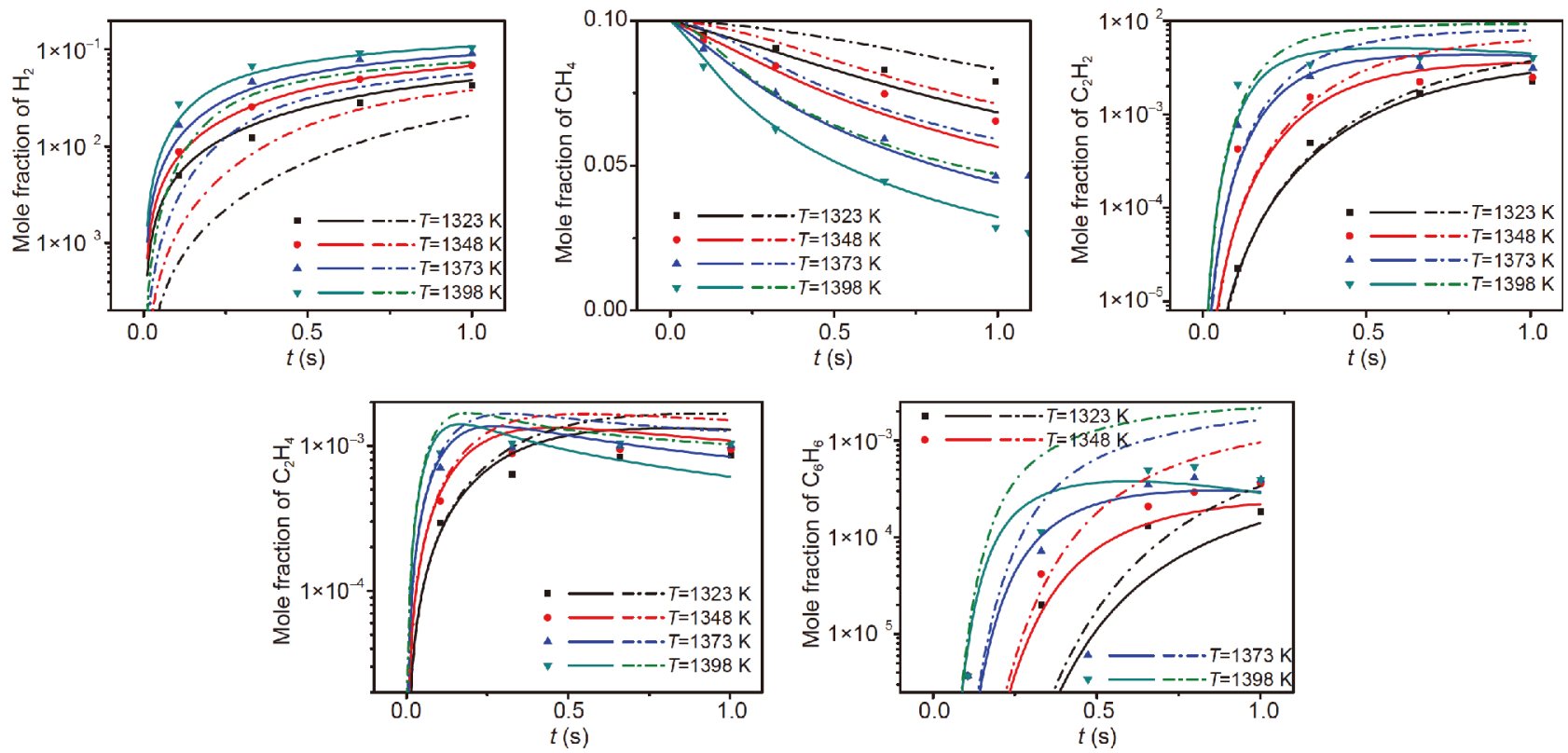

Figure 8 Mole fraction variations of gas species at different residence times and different temperatures. Symbols: experimental results; dash dot lines: simulation results with previous heterogeneous elementary reactions and solid lines: simulation results with present "apparent" homogeneous reactions.

the present mechanism and compared with the experimental data and simulation results of previous mechanisms, as shown in Fig. 8. Symbols represent the experimental data, while solid lines and dash dot lines are the present and previous simulation results with pyrocarbon deposition. The mole fractions of main gases from the previous heterogeneous mechanisms have no apparent difference with the simulation results based on the homogeneous mechanism and deviate from the experimental results. Good agreements are shown between the experimental and present simulation results. No overconsumption of the precursors for pyrocarbon deposition is observed when all the heterogeneous reactions are involved without adjusting the kinetic parameters. The mole fraction of acetylene is almost constant at long residence times for each temperature. The reductions of benzene at long residence times and high temperatures are correctly reproduced by present simulations. The underestimation of methane and benzene mole fractions at low temperatures is due to the inaccurate kinetic parameters of homogeneous reactions in methane pyrolysis, which has been analyzed previously in the single species deposition.

\section{GLOBAL MODEL FOR PYROCARBON FORMATION WITH DIFFERENT TEXTURES}

In the previous section, precursors for pyrocarbon de- position have been identified and discussed. With the increase of the temperature, more gas intermediates are produced in methane pyrolysis and the precursors for pyrocarbon deposition vary from a single reactant species to a combination of small species and aromatic hydrocarbons. The mechanism of pyrocarbon deposition is firstly discussed based on these precursors. It should be noted that deposition mechanism and formation mechanism of pyrocarbon are distinguished from each other, although in most discussions they are used equally. Pyrocarbon deposition mechanism only focuses on surface reactions between the gas and the surface, which results more carbon atoms on the surface or to be considered as part of the solid [40]. On the other hand, pyrocarbon formation mechanism is the chemistry of carbon formation, describing the formation of different textures [13].

According to the present knowledge, the deposition of pyrocarbon has two mechanisms: a growth mechanism and a nucleation mechanism [40]. The growth mechanism expresses that carbon grows by the chemisorption of gas intermediates at the active sites (mainly at the edge of existing layers). This implies that an active site is essential for pyrocarbon deposition. Yet, no size limitation for the gas intermediates is set, which signifies that either small linear species or aromatic species can be involved. In this study, the gases are $\mathrm{CH}_{x(x \leq 4)}$, acetylene, benzene and polyaromatic hydrocarbons. The nucleation mechanism 


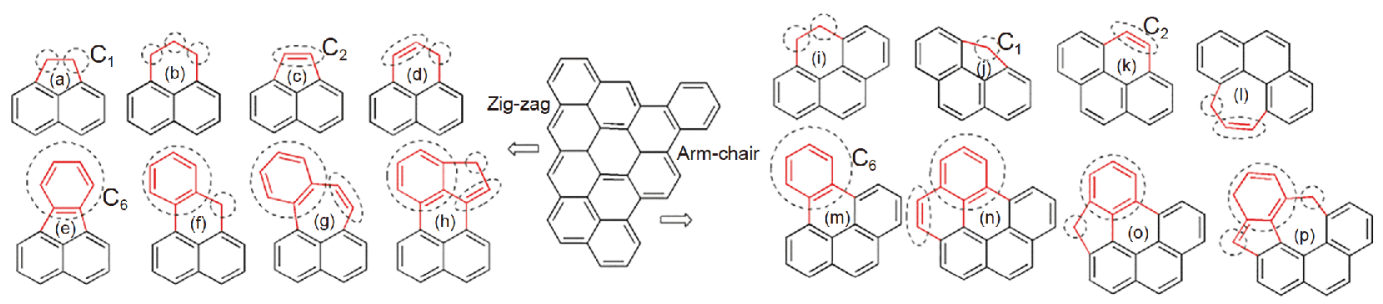

Figure 9 Schematics of pyrocarbon deposition in atoms with carbon addition from $\mathrm{C}_{1}\left(\mathrm{CH}_{x(x \leq 4)}\right), \mathrm{C}_{2}$ (acetylene), $\mathrm{C}_{6}$ (aromatic hydrocarbon) and their combinations. (a-h) new atoms on zig-zag sites and (i-p) new atoms on arm-chair sites.

is the physisorption of large polyaromatic hydrocarbons on the surface, developing new carbon layers. This mechanism is favored when large polyaromatic hydrocarbons are in large mole fractions and no active sites are available. The mechanism has been ignored when establishing the heterogeneous reactions of pyrocarbon deposition in the previous section. According to the deposition rates in this work, the mechanism should have happened at $1,398 \mathrm{~K}$, evidenced from the deviation between the simulation result and the experimental data. A similar result had been concluded in previous experiments [12]. As no accurate data of each large polyaromatic hydrocarbons are presented in this work and physisorption seems to be less important in the carbon deposition, the nucleation mechanism will not be discussed further.

In the growth mechanism, active sites on the surface edges are mainly arm-chair sites and zig-zag sites [13]. The growth of pyrocarbon layers should be relevant to the mechanism of aromatic growth in the gas phase, despite the different transition state and much stronger effects of steric factors. Dominant surface reactions are hydrogen abstraction-carbon addition, followed by dehydrocyclization. Fig. 9 depicts schematics of pyrocarbon deposition in atoms with carbon addition from $\mathrm{C}_{1}\left(\mathrm{CH}_{x(x \leq 4)}\right), \mathrm{C}_{2}$ (acetylene), $\mathrm{C}_{6}$ (aromatic hydrocarbon) and their combinations. Aromatic hydrocarbon depositions in atoms are represented by that of benzene according to their similar structures for the sake of conciseness. For zig-zag sites, three additional carbons are needed to form a new hexagonal ring, which can be $\mathrm{C}_{1}$ (Fig. 9b) or a combination of $\mathrm{C}_{1}$ and $\mathrm{C}_{2}$ (Fig. 9d). The addition of $\mathrm{C}_{6}$ on zigzag sites produces a biphenyl type bond first and then dehydrocyclizes to form a pentagon ring (Fig. 9e). Pentagon rings can also be formed by additions of $\mathrm{C}_{1}$ (Fig. 9a) or $\mathrm{C}_{2}$ (Fig. 9c). Small molecule depositions beside biphenyl type bonds within $\mathrm{C}_{6}$ deposition lead to pentagon rings (Fig. 9h), hexagonal rings (Fig. 9f) or heptagon rings (Fig. 9g) by dehydrocyclization or isomerization. For arm-chair sites, a new hexagonal ring can
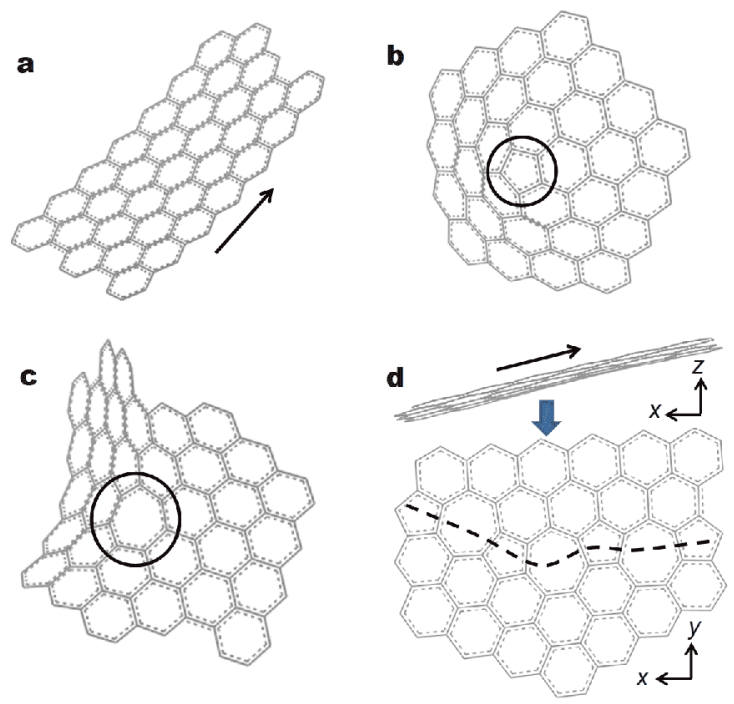

Figure 10 Schematics of pyrocarbon formation in layers. (a) a highlyoriented layer with hexagonal rings, (b) a disordered layer with pentagon rings, (c) a disordered layer with heptagon rings, and (d) a highlyoriented layer with pentagon-heptagon pairs.

be produced by a single kind of species, as shown in Fig. $9 \mathrm{i}, \mathrm{k}$ or $\mathrm{m}$. The arm-chair site could close rapidly with an addition of $\mathrm{C}_{1}$, forming a pentagon ring (Fig. 9j). Combinations of different species condense on arm-chair sites forming new structures, for example, a pentagon ring by $\mathrm{C}_{1}$ and $\mathrm{C}_{6}$ deposition (Fig. 9o), a hexagonal ring by $\mathrm{C}_{2}$ and $\mathrm{C}_{6}$ deposition (Fig. $9 \mathrm{n}$ ), or a heptagon ring and a heptagon ring by $\mathrm{C}_{1}$ and $\mathrm{C}_{6}$ deposition (Fig. 9p). Note that the above discussion with Fig. 9 only gives a lump consideration of pyrocarbon deposition with different species and does not mean the real deposition process, which is certainly much more complicated.

Repeating the pyrocarbon deposition in atoms, carbon layers are formed. Fig. 10 shows schematics of pyrocarbon formation in layers. The hexagonal rings form a perfect structure with a highly oriented planar layer (Fig. 10a), while the individual formations of pentagon or heptagon rings bring defects in the carbon layers and destroy the planar structure, as shown in Fig. 10b and c. 
The pair formations of pentagon and heptagon rings also lead to a highly-oriented carbon layer (Fig. 10d), which has been observed in regenerative laminar pyrocarbon with high texture [41,42]. Based on the model, several conclusions are obtained with respect to the pyrocarbon formation with different textures. At $1,323 \mathrm{~K}$, very limited ways of pyrocarbon deposition of pentagon and hexagonal rings are available as $C_{1}$ is the only precursor, leading to a low deposition rate and a low textured pyrocarbon. When the temperature increases, the maturation of gases increases and acetylene, benzene and polyaromatic hydrocarbons join the pyrocarbon deposition process. The texture of deposited pyrocarbon increases with the increasing degree of gas maturation. Hexagonal rings can be produced by adding one species or a combination of several species and disorders from pentagon rings or heptagon rings could be eliminated by making a pair of them, showing that highly oriented planar layers with larger deposition rates are easier to be formed. These are supported by the experimental results. An increasing of orientation angles in pyrocarbon has been observed with the increase of the temperature [12]. Extinction angle tests have shown that pyrocarbon formed at $1,343 \mathrm{~K}$ is in medium texture while that at $1,368 \mathrm{~K}$ is in high texture [11].

\section{CONCLUSION}

A new model of methane pyrolysis for CVI of pyrocarbon is presented in this paper, which contains a detailed homogeneous reaction mechanism describing the gas phase reactions with elementary reactions and a lumped heterogeneous reaction mechanism with lumped surface reactions for pyrocarbon deposition. Mole fractions of main gas intermediates and deposition rates of pyrocarbon in the temperature range of $1,323-1,398 \mathrm{~K}$ with a flow reactor are reproduced well without any adjusting parameters by the model. The precursors for pyrocarbon deposition at different temperatures alter: $\mathrm{C}_{1}$ species at $1,323 \mathrm{~K}$, a combination of $\mathrm{C}_{1}$, acetylene and benzene at $1,348 \mathrm{~K}$ and extra contributions from large polyaromatic hydrocarbons at 1,373 and $1,398 \mathrm{~K} . \mathrm{C}_{1}$ species is the principle source of pyrocarbon deposition in all temperatures, which has been proved by its large concentration in the gas phase and large kinetic parameters of the deposition reaction. As a result of pyrocarbon deposition, mole fractions of consumed methane and produced hydrogen increase noticeably. Acetylene deposition prevents the boost of its mole fractions at long residence times. Pyrocarbon deposited from benzene and large polyaromatic hydrocarbons shows more proportions at high temperatures, illustrating the decreasing mole fractions at long residence times in the gas phase. The growth mechanism, namely, carbon additions at the active sites, is the main mechanism for pyrocarbon deposition. Based on the precursors of pyrocarbon deposition, formation mechanisms of pyrocarbon with different textures reveal that pyrocarbon with a high texture is more likely to be formed by hexagonal rings and pentagon-heptagon pairs in a mature gas phase. Otherwise, lower textured pyrocarbon is formed with defects induced by pentagon rings or heptagon rings. The results have been confirmed by experiments.

There remains complementary work to strengthen the accurate quantity and general applicability of the conclusions in this work. Gas concentrations of large polyaromatic hydrocarbons in methane pyrolysis are essential to improve the prediction of pyrocarbon deposition rates at high temperatures. Information of the deposition surface would help identify the density of active sites in reality. Encouraging results from experiments, for example, atomic resolution imaging by high resolution transmission electron microscopy [43], are expected to reveal the heterogeneous steps in the real process of pyrocarbon formation.

Received 1 October 2018; accepted 29 November 2018; published online 24 December 2018

1 Wang C, Murugadoss V, Kong J, et al. Overview of carbon nanostructures and nanocomposites for electromagnetic wave shielding. Carbon, 2018, 140: 696-733

2 Li K, Zhang J. Recent advances in flexible supercapacitors based on carbon nanotubes and graphene. Sci China Mater, 2018, 61: 210232

3 Chen Y, Shi J. Mesoporous carbon biomaterials. Sci China Mater, 2015, 58: 241-257

4 Chowdhury P, Sehitoglu H, Rateick R. Damage tolerance of carbon-carbon composites in aerospace application. Carbon, 2018, 126: $382-393$

5 Mikociak D, Blazewicz S, Michalowski J. Biological and mechanical properties of nanohydroxyapatite-containing carbon/carbon composites. Int J Appl Ceram Technol, 2012, 9: 468-478

6 Cao S, Li H, Lu J, et al. Unique cytological behavior of $\mathrm{MC}_{3} \mathrm{~T}_{3}-\mathrm{E}_{1}$ osteoblasts on $\mathrm{H}_{2} \mathrm{O}_{2}$-modified $\mathrm{C} / \mathrm{C}$ composites in vitro. Sci China Mater, 2017, 60: 361-367

7 Jia Y, Li K, Xue L, et al. Mechanical and electromagnetic shielding performance of carbon fiber reinforced multilayered (PyC-SiC) matrix composites. Carbon, 2017, 111: 299-308

8 Liu X, Yin X, Kong L, et al. Fabrication and electromagnetic interference shielding effectiveness of carbon nanotube reinforced carbon fiber/pyrolytic carbon composites. Carbon, 2014, 68: 501510

9 Reznik B, Hüttinger KJ. On the terminology for pyrolytic carbon. Carbon, 2002, 40: 621-624

10 Benzinger W, Hüttinger KJ. Chemistry and kinetics of chemical vapor infiltration of pyrocarbon-IV. Investigation of methane/hy- 
drogen mixtures. Carbon, 1999, 37: 931-940

11 Zhang WG, Hu ZJ, Hüttinger KJ. Chemical vapor infiltration of carbon fiber felt: optimization of densification and carbon microstructure. Carbon, 2002, 40: 2529-2545

12 Hu ZJ, Zhang WG, Hüttinger KJ, et al. Influence of pressure, temperature and surface area/volume ratio on the texture of pyrolytic carbon deposited from methane. Carbon, 2003, 41: 749-758

13 Dong GL, Hüttinger KJ. Consideration of reaction mechanisms leading to pyrolytic carbon of different textures. Carbon, 2002, 40: 2515-2528

14 Norinaga K, Deutschmann O, Hüttinger KJ. Analysis of gas phase compounds in chemical vapor deposition of carbon from light hydrocarbons. Carbon, 2006, 44: 1790-1800

15 Norinaga K, Deutschmann O. Detailed kinetic modeling of gasphase reactions in the chemical vapor deposition of carbon from light hydrocarbons. Ind Eng Chem Res, 2007, 46: 3547-3557

16 Devin-Ziegler I, Fournet R, Marquaire PM. Pyrolysis of propane for CVI of pyrocarbon: Part I. Experimental and modeling study of the formation of toluene and aliphatic species. J Anal Appl Pyrolysis, 2005, 73: 212-230

17 Devin-Ziegler I, Fournet R, Marquaire PM. Pyrolysis of propane for CVI of pyrocarbon: Part II. Experimental and modeling study of polyaromatic species. J Anal Appl Pyrolysis, 2005, 73: 231-247

18 Devin-Ziegler I, Fournet R, Marquaire PM. Pyrolysis of propane for CVI of pyrocarbon: Part III: Experimental and modeling study of the formation of pyrocarbon. J Anal Appl Pyrolysis, 2007, 79: 268-277

19 Benzinger W, Hüttinger KJ. Chemical vapour infiltration of pyrocarbon: I. Some kinetic considerations. Carbon, 1996, 34: 14651471

20 Becker A, Hüttinger KJ. Chemistry and kinetics of chemical vapor deposition of pyrocarbon-IV Pyrocarbon deposition from methane in the low temperature regime. Carbon, 1998, 36: 213-224

21 Becker A, Hüttinger KJ. Chemistry and kinetics of chemical vapor deposition of pyrocarbon-V Influence of reactor volume/deposition surface area ratio. Carbon, 1998, 36: 225-232

22 Brüggert M, Hu Z, Hüttinger KJ. Chemistry and kinetics of chemical vapor deposition of pyrocarbon: VI. Influence of temperature using methane as a carbon source. Carbon, 1999, 37: 20212030

23 Becker A, Hüttinger KJ. Chemistry and kinetics of chemical vapor deposition of pyrocarbon-II Pyrocarbon deposition from ethylene, acetylene and 1,3-butadiene in the low temperature regime. Carbon, 1998, 36: 177-199

$24 \mathrm{Hu} \mathrm{C}$, Li H, Zhang S, et al. A molecular-level analysis of gas-phase reactions in chemical vapor deposition of carbon from methane using a detailed kinetic model. J Mater Sci, 2016, 51: 3897-3906

25 Becker A, Hüttinger KJ. Chemistry and kinetics of chemical vapor deposition of pyrocarbon-III Pyrocarbon deposition from propylene and benzene in the low temperature regime. Carbon, 1998, 36: 201-211

26 Hidaka Y, Nakamura T, Tanaka H, et al. Shock tube and modeling study of propene pyrolysis. Int J Chem Kinet, 1992, 24: 761-780

27 Tsang W. Chemical kinetic data base for combustion chemistry Part V. Propene. J Phys Chem Reference Data, 1991, 20: 221-273

28 Marinov NM, Pitz WJ, Westbrook CK, et al. Modeling of aromatic and polycyclic aromatic hydrocarbon formation in premixed methane and ethane flames. Combust Sci Tech, 1996, 116-117: 211287

29 Richter H, Howard JB. Formation and consumption of single-ring aromatic hydrocarbons and their precursors in premixed acetylene, ethylene and benzene flames. Phys Chem Chem Phys, 2002, 4: 2038-2055

30 Norinaga K, Deutschmann O, Saegusa N, et al. Analysis of pyrolysis products from light hydrocarbons and kinetic modeling for growth of polycyclic aromatic hydrocarbons with detailed chemistry. J Anal Appl Pyrolysis, 2009, 86: 148-160

31 Gilbert RG, Luther K, Troe J. Theory of thermal unimolecular reactions in the fall-off range. II. Weak collision rate constants. Berichte der Bunsengesellschaft für physikalische Chem, 1983, 87: 169-177

$32 \mathrm{Qu} \mathrm{Y}$, Su K, Wang X, et al. Reaction pathways of propene pyrolysis. J Comput Chem, 2010, 34: 1421-1442

$33 \mathrm{Hu} \mathrm{Z}$, Hüttinger KJ. Chemistry and kinetics of chemical vapor deposition of pyrocarbon: VIII. Carbon deposition from methane at low pressures. Carbon, 2001, 39: 433-441

34 Frenklach $M$, Wang $H$. Detailed surface and gas-phase chemical kinetics of diamond deposition. Phys Rev B, 1991, 43: 1520-1545

35 Lacroix R, Fournet R, Ziegler-Devin I, et al. Kinetic modeling of surface reactions involved in CVI of pyrocarbon obtained by propane pyrolysis. Carbon, 2010, 48: 132-144

36 Tang ZP, Li AJ, Zhang ZW, et al. Chemistry and kinetics of heterogeneous reaction mechanism for chemical vapor infiltration of pyrolytic carbon from propane. Ind Eng Chem Res, 2014, 53: 17537-17546

37 Li S, Petzold L. Software and algorithms for sensitivity analysis of large-scale differential algebraic systems. J Comput Appl Math, 2000, 125: 131-145

38 Li A, Deutschmann O. Transient modeling of chemical vapor infiltration of methane using multi-step reaction and deposition models. Chem Eng Sci, 2007, 62: 4976-4982

39 Manion JA, Huie RE, Levin RD, et al. NIST Chemical Kinetics Database. Available from URL: http://kinetics.nist.gov/

40 Hu ZJ, Hüttinger KJ. Mechanisms of carbon deposition-a kinetic approach. Carbon, 2002, 40: 624-628

41 Farbos B, Weisbecker P, Fischer HE, et al. Nanoscale structure and texture of highly anisotropic pyrocarbons revisited with transmission electron microscopy, image processing, neutron diffraction and atomistic modeling. Carbon, 2014, 80: 472-489

42 Leyssale JM, Da Costa JP, Germain C, et al. Structural features of pyrocarbon atomistic models constructed from transmission electron microscopy images. Carbon, 2012, 50: 4388-4400

43 He K, Robertson AW, Lee S, et al. Extended Klein edges in graphene. ACS Nano, 2014, 8: 12272-12279

Acknowledgements This work was supported by the National Natural Science Foundation of China (51521061 and 51472203), the "111" Project (B08040), and the Research Fund of State Key Laboratory of Solidification Processing (NWPU), China (142-TZ-2016).

Author contributions $\mathrm{Hu} \mathrm{C}$ and $\mathrm{Li} \mathrm{H}$ designed the models; $\mathrm{Hu} \mathrm{C}$ performed the modeling; Hu C, Zhang $\mathrm{S}$ and Li W contributed to the data analysis. Hu C and Li N wrote the paper. All authors contributed to the general discussion.

Conflict of interest The authors declare that they have no conflict of interest.

Supplementary information Supporting data are available in the online version of the paper. 

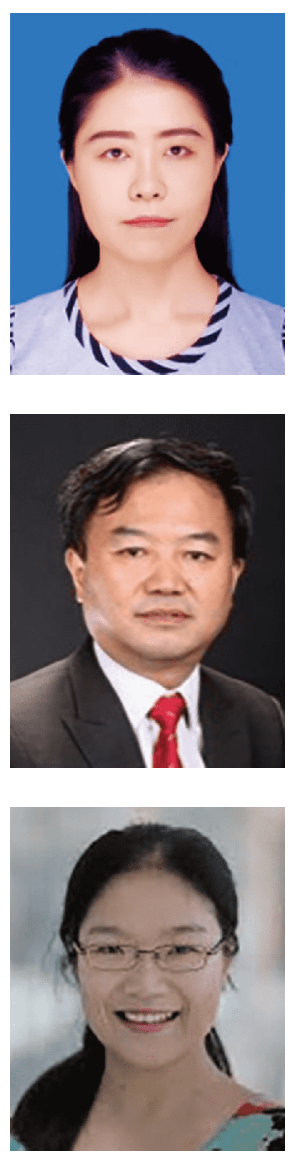

Chunxia Hu is currently a PhD student at the School of Materials Science and Engineering, Northwestern Polytechnical University. Her research focuses on the manufacturing and properties of advanced carbon/carbon composites.
Hejun Li is a professor at the School of Materials Science and Engineering, Northwestern Polytechnical University. He received his PhD degree from Harbin Institute of Technology in 1991. His current research interests include advanced carbon/carbon composites, anti-oxidation coatings, paper based friction materials and nanomaterials.
Ni Li is now working in the College of Engineering, Computer Science, and Technology, Department of Mechanical Engineering, California State University, Los Angeles, USA. She received her PhD degree from the University of Central Florida, USA, in 2013. Her current research interests include dynamics and kinematics; optimization; control; instrument; and sensor design.

\section{甲烷化学气相沉积不同织构热解碳的动力学分析}

胡春霞 ${ }^{1}$, 李贺军 ${ }^{1 *}$, 张守阳 ${ }^{1}$, 李伟 $^{1}$, 李霓 $^{2^{*}}$

摘要 本文建立了一种甲烷化学气相沉积不同织构热解碳的动力学模型. 该模型包括甲烷气相热解的详细基元反应及热解碳沉积的集总 表面反应, 模拟了1323-1398 K立式热壁反应炉中热解碳沉积过程中不同气体的组分浓度及热解碳的沉积速率, 且模拟结果优于已有报道 的模型、与实验结果吻合良好. 结果表明, 热解碳的主要沉积机理为碳源气体在表面活性位的生长机理, 其中 $\mathrm{C}_{1}$ 物质为主要碳源气体. 随 着温度升高, 甲烷热解混合气体趋于成熟, 乙炔、苯和多环芳香烃逐渐成为重要的碳源气体. 基于以上碳源气体的热解碳形成机理分析指 出热解混合气体的成熟有利于形成由六元环及五元环-七元环组合而成的高定向平面结构, 即高织构热解碳, 与实验结论吻合良好. 